\title{
Xul Solar. Una mirada artística sobre la idea de identidad latinoamericana
}

\author{
Xul Solar. An artistic view about the idea of Latin American identity
}

\author{
Agustín Bucari agustinbucari@gmail.com \\ Instituto de Historia del Arte Argentino y Americano; Facultad de Bellas Artes; \\ Universidad Nacional de La Plata (Argentina)
}

\section{Resumen}

En este artículo se describirán algunos vínculos que Xul Solar mantiene con la escena artística y cultural del país, y también del extranjero, con el objetivo de desarrollar su visión acerca de la idea de identidad latinoamericana. A partir del análisis de tres producciones del artista es posible vislumbrar la importancia de su participación en el ámbito intelectual de la década del 20, en especial, a través de su actividad en revistas como Martín Fierro y Proa. En este sentido, tanto el pensamiento como la obra de Xul Solar inciden en la construcción de visiones posibles sobre la 
identidad latinoamericana: el rol del pasado, la historia y los orígenes de esta región son ejes centrales en la construcción del proyecto plástico del artista y de sus ideas utópicas de integración.

Palabras clave: Xul Solar; identidad; Latinoamérica; revista Proa.

\section{Abstract}

This essay will describe some links that Xul Solar maintains with the artistic and cultural scene of the country, and also from abroad, with the aim of developing his vision about the idea of Latin American identity. From the analysis of three productions of the artist it is possible to glimpse the importance of his participation in the intellectual field of the 20s, especially, through his activity in magazines such as Martín Fierro and Proa. In this sense, both the thought and the work of Xul Solar affect the construction of possible visions about Latin American identity: the role of the past, the history and the origins of this region are central axes in the construction of the artist's visual project and of his utopian ideas of integration.

Keywords: Xul Solar; identity; Latin America; Proa magazine.

Honremos a los que pugnan para que el alma de la patria sea más bella. Porque no terminaron aún para nuestra América las guerras de la Independencia

Xul Solar (1924)

Oscar Agustín Alejandro Schulz Solari, conocido artísticamente como Xul Solar, nació el 14 de diciembre de 1887 en la ciudad de San Fernando, Buenos Aires, Argentina. Hijo de Emilio Schulz Riga de profesión ingeniero (Riga, Letonia, 1853-Buenos Aires, 1925) y Agustina Solari (San Pietro di Roveretto, Italia, 1865-Buenos Aires, 1958), vivió su infancia en la localidad de San Fernando, para luego trasladarse a la Capital Federal, donde finalizó sus estudios secundarios en el Colegio Nacional de Seccional Norte (Tedín de Tognetti, 2006).

La ciudad de Buenos Aires del centenario atravesaba cambios convulsivos, ya sea desde el punto de vista cultural producto de las olas inmigratorias, como espacial, a causa de la 
urbanización acelerada de las capitales modernas. En este contexto, Alejandro Schulz Solari decide irse al viejo continente, en 1912 se embarca en el Highland Carrier rumbo a Londres para buscar allí en sus raíces europeas.

El viaje a Europa como lugar de formación de artistas ha sido, por lo menos hasta mediados del siglo XX (cuando Estados Unidos se afianza como centro artístico), una constante en los artistas argentinos. Xul Solar se desplaza a Europa sin recibir becas ni patrocinio de ninguna institución, como sí obtuvo, por ejemplo, su compañero el artista Emilio Pettoruti. Luego de haber transitado por Londres, París y Florencia, entre otras localidades europeas, ambos artistas deciden instalarse en 1921 en la ciudad de Munich. Allí, se relaciona con la filosofía de Rudolf Steiner, asiste a sus conferencias sobre la corriente antroposófica y la Escuela Waldorf. Este filósofo es de gran importancia para Xul Solar, así como para sus contemporáneos artistas alemanes fundadores de la Bauhaus, en muchos sentidos, ya sea desde su perspectiva filosófica de integración entre arte, ciencia y religión, como sus aportes estrictamente culturales. En Munich, el artista también acudió a los cursos que impartían en los Münchener Kunstwerkstätten fundados por Wilhelm von Debschitz (Talleres de arte y enseñanza de artes decorativas), en el misma institución donde había estudiado he impartido clase Paul Klee. El interés, tanto por Klee como por Kandinsky, está documentado en una de las primeras cartas que Xul le escribe a su familia:

Me compré un libro, Der Blue Reiter, sobre el arte más avanzado, de los fauves, futuristas y cubistas ... Cosas que no me gustan mucho la verdad, pero estoy satisfechísimo porque veo como yo solo, sin inspiración exterior de ninguna clase, he trabajado en la tendencia que será la dominante del arte más elevado del porvenir (Abós, 2017: 50).

Vive durante un tiempo en Baviera junto a Pettoruti en los agitados años de las revoluciones de las comunas, Europa transita la posguerra, Alemania está diezmada, y por dicha situación deciden volver. En 1924 Xul Solar y Pettoruti regresan al país para dar el golpe moderno al atrasado arte argentino. Una vez en Argentina, Xul Solar forma parte activa de los intelectuales de la década del 20, que buscan en el criollismo una respuesta a la necesidad de renovación moderna. El rescate de la tradición hispana se constituyó como respuesta a las doctrinas imperialistas norteamericanas y europeas, dicho fenómeno que comenzó con la generación del centenario, entre ellos Rojas e Ingenieros, derivó más tarde en los movimientos vanguardistas con un conjunto de premisas políticas e ideologías definidas (Sarlo, 1988: 105). Xul Solar es afín a estas premisas y colabora como pintor, ilustrador y escritor en las revistas Martín Fierro (1) y Proa, entre otras. Acompaña los movimientos de la prensa, principalmente a aquellos ligados al 
grupo Florida y al pequeño grupo de intelectuales que lo componían, entre otros, Jorge Luis Borges, Macedonio Fernández, Leopoldo Marechal y Oliverio Girondo. Estos intelectuales de la época escribían acerca de la configuración de nuevas vías artísticas que respondiesen a la crisis cultural moderna que eclosionaba desde principios de 1880 y se profundizó en los años veinte.

Si bien la prensa gráfica en la Argentina había sido de gran importancia en su relación con la opinión pública y la política, como es el caso de la revista Don Quijote o Caras y Caretas (que según Alem habían contribuido a la revolución al igual que las armas) (Gallo, 2006: 103). Las revistas fundadas a partir del 20 tienen otra característica, suelen estar más orientadas a contenidos literarios, cuentos, poemas, críticas artísticas en consonancia con alguna vanguardia europeas, más que a caricaturas y reseñas de actualidad como sí lo eran las revista fundadas en el siglo XIX que presentaban un claro posicionamiento político partidario (2). El nacionalismo cultural como lo describen Altamirano y Sarlo (1997: 111) germina en las esferas intelectuales de la época, la figura del artista, y más aún, las comunidades o pequeños grupos de profesionales (los casos paradigmáticos de Florida y Boedo) discuten y reflotan los debates acerca de la identidad nacional, el ser nacional y la cultura local que se había suscitado a principios de siglo (Sarlo, 2002: 44-45). Por ejemplo el caso del debate Lugones-Borges acerca del papel del Martín Fierro en la literatura argentina y su rol en la conformación de la identidad nacional exhibe de forma clara tanto el clima social de debate como el lugar y soportes del mismo, en tanto que dicha polémica se va construyendo artículo a artículo. En este contexto pueden nombrarse varias publicaciones de la época que buscan consolidar y dar lugar a las nuevas expresiones modernas del Río de la Plata: Martín Fierro, Proa, Sur (Florida), Los pensadores, Dínamo, Extrema izquierda (Boedo).

La revista Martín Fierro alcanza su mayor grado de apertura americanista en 1925, como consecuencia de los viajes de Oliverio Girondo por el continente americano (Artundo, 2001). En ese mismo año, la renovación del diseño de la revista incorporó doce motivos precolombinos a sus páginas, dando coherencia a su programa de acción militante que pretendía la unión de la juventud intelectual y artística latinoamericana en clave de emancipación. En este marco se presenta la colaboración de Xul Solar en la revista Proa, con un boceto (Figura 1) y una acuarela (Figura 2) que llevan el nombre de la revista, las cuales fueron exhibidas en el Museo Nacional de Bellas Artes (MNBA) en la muestra Xul Solar Panactivista (Rabossi, 2017). Este grupo de ilustraciones son un claro ejemplo del servicio que Xul Solar propiciaba a sus compañeros de la cultura porteña, en tanto que, por medio del lenguaje plástico visual, simbolizaba aquellos ideales propuestos en el criollismo de vanguardia y reforzaba la línea emancipadora de los editores. 
Las dos obras fueron expuestas contiguamente en el MNBA en el sector dedicado a la participación de Xul Solar en las publicaciones impresas, tanto editoriales como gráficas. La comparación entre una obra y otra nos permite observar aquello que el artista eliminó, lo que fue mantenido y los elementos agregados posteriormente. Quizás una de las supresiones más significativas sea la reserva de la información escrita, en el boceto aparece la frase "Proa revista de vanguardia", el cual es simplificado a Proa en el segundo caso. La vanguardia, sin embargo, es reforzada en sus elementos visuales, en tanto figura militarizada, se agregan las espadas de los intelectuales que comandan el barco, por delante de la proa. Este es un claro ejemplo de la estrategia de escritura visual cercana al jeroglífico que practica Xul en sus obras, en la primera versión Proa y vanguardia estaban relacionadas en tanto palabras, en la segunda versión, la palabra proa se superpone a la zona que la representa como tal en la embarcación y se le suma a su vez una vanguardia de espadas combativas. Existe un diálogo entre los textos verbales y los elementos compositivos: las palabras dan cuenta de las representaciones visuales a la manera de un señalamiento (el personaje superior esta yuxtapuesto a la sigla Genio, así como el acantilado, la tierra está en contacto con la palabra El Dorado).

Son cuatro textualidades dentro del cuadro y una por fuera del marco, de los primeros dos pares cada uno tiene su opuesto y se disponen persistiendo esta variación: Xul Solar se emplaza de abajo hacia arriba en la zona inferior izquierda; El Dorado, de arriba hacia abajo superior derecho; Proa, de izquierda a derecha en transición del cuadrante inferior al superior, y, cuando llegamos al elemento del Genio, vemos que para seguir esta lógica debería estar invertida la lectura de derecha izquierda, pues bien, la operatoria de Xul en este caso es invertir la figura del genio propiamente dicha y privilegiar la legibilidad de la palabra genio. Esta forma de componer, de correspondencias rítmicas, variaciones del motivo, se aproximan a lo musical (Cristía, 2007), lenguaje al cual Xul Solar estaba habituado (había estudiado violín en su infancia), y también se replica a lo largo de sus obras, sobre todo aquellas en las que prevalece la matriz bidimensional (3).

Sobre el lado derecho, en las dos composiciones se mantiene la tierra con el árbol, con las palabras El Dorado. Este señalamiento representa la tierra prometida americana, el lugar utópico que la vanguardia criolla busca alcanzar. Esta transición en el ascenso es un motivo recurrente en la obra de Xul Solar y coincidimos con Ángeles Smart:

El doble sentido etimológico del término utopía cobra aquí su total significación: úтотоৎ, el "no-lugar" que existe sólo en nuestra imaginación aspira e inspira dinámicamente a la realización del źuтотоৎ, el "buen lugar", el lugar de la felicidad. Es en el arte donde la 
pluralidad de mundos posibles es concebida y nombrada, iniciando, así, el advenimiento del primer surgir y aparecer de toda realidad, cualquiera sea. Proa y Drago proyectan la utopía del ascenso de la humanidad hacia una dimensión superior, dimensión que si bien no vemos en los cuadros está presente más que ninguna otra cosa, como aquello hacia donde todo se dirige, todo tiende, todo aspira (Smart, 2010: 95).

De forma plástica, la zona a la cual se dirige la proa, es un no-lugar, en el sentido es análogo al fondo, al soporte de la imagen, es literalmente, un lugar no llenado, negativo y a su vez es presentado como el dorado, el buen lugar, el lugar positivo (de Rueda, 2003: 15) (4). Así mismo, la proa de la embarcación se posa sobre la diagonal ascendente de la composición, así como su vértice indica la direccionalidad que converge en la zona antes mencionada.

Xul Solar ofrece una síntesis gráfica de las pretensiones manifiestas del conjunto particular, en este caso los intelectuales martinfierristas, en una propuesta visual concreta, en otras palabras, crea un imaginario que conforma la identidad de la revista. De la misma manera, en su obra pictórica intenta construir un sistema de símbolos que den forma a lo que él entiende como identidad latinoamericana: ya no son los pequeños intelectuales portadores de la bandera argentina los protagonistas de la acción sino los pueblos de lberoamérica los que se embarcan hacia la tierra prometida utópica de la América grande.

El pensamiento y la obra de Xul Solar inciden en la construcción de visiones posibles sobre la identidad latinoamericana. El rol del pasado, la historia y los orígenes de esta región son ejes centrales en la construcción del proyecto plástico del artista y de sus ideas utópicas de integración. Por estos años, América Latina está dando al mundo -convulsionado por la posguerra- un gran ejemplo de convivencia, confraternidad y respeto mutuo. Xul Solar desea consolidar la buena vecindad latinoamericana con la creación de un idioma común, el neocriollo y luego la Pan-lengua, compuesto por palabras, sílabas y raíces sacadas de las dos lenguas dominantes de centro y Sudamérica, el castellano y el portugués (Abós, 2017: 239).

Según Eduardo Grüner la categoría identidad es un concepto burgués, moderno y occidental ligado a la representación (Grüner, 2004: 3). En consecuencia, los agentes productores de iconografías, como los artistas, son parte importante en la formación de la idea de identidad en el sentido de la circulación y el consumo de dichos imaginarios simbólicos (en el mismo sentido que la revista Proa). Los artistas modernos, pertenecientes a las vanguardias históricas, han sido una pieza fundamental en esta construcción latinoamericana pues, para Jorge Larraín, identidad y modernidad son parte del mismo proceso:

A diferencia de estas teorías absolutistas que presentan la modernidad y la identidad en 
América Latina como fenómenos de alguna manera mutuamente excluyentes, yo veo su continuidad e imbricación. El mismo proceso histórico de construcción de identidad, es, desde un determinado momento, un proceso de construcción de la modernidad (Larraín, 1997: 2).

La modernidad como fenómeno global es asimilada de manera activa por los distintos agentes de la cultura, así como también, de la política de América Latina. Lo dice el propio Xul Solar cuando proclama la liberación de la América Ibérica: "Asimilemos sí, lo digerible" (Artundo, 2001: 3) frase en concordancia con el manifiesto antropófago que se publicaba en esa época (5). Tanto para un proyecto visual plástico moderno como para un proyecto de país moderno es necesaria una conciencia de la historia, de los orígenes y del lugar del futuro, como utopía y, sobre todo, una visión de lo otro. Así, Xul Solar se inscribe en los nuevos movimientos de vanguardia que discuten con la antigua manera de ver el arte al servicio de la mímesis y la representación realista. Intenta romper las cadenas invisibles que lo atan al viejo continente para conquistar nuevos terrenos plásticos desde y para Latinoamérica. Identidad y modernidad van ligadas en la obra de Xul Solar así como en la conformación de las ideas y posturas políticas de la época, su obra debe entenderse como producto y ejemplificación de los debates históricos e historiográficos.

En este sentido, la obra País de 1925 (Figura 3) expone la idea de integración regional que tiene el artista, tal como argumenta Sabrina Gil: en el regreso de Xul Solar hay una ruptura con el viejo nuevo continente, la búsqueda de un arte nuevo también implicó la necesidad de asentar plásticamente un horizonte común latinoamericano en la historia (Gil, 2012: 3). Con Pettoruti deciden alejarse del gaucho (6) y recurrir a motivos primitivistas (al igual que lo hicieron los modernos alemanes):

Somos y nos sentimos nuevos, a nuestra meta nueva no conducen caminos viejos y ajenos. Diferenciémonos. Somos mayores de edad y aún no hemos terminado las guerras pro independencia. Acabe ya la tutela moral de Europa. Asimilemos sí, lo digerible, amemos a nuestros maestros; pero no queramos más nuestras únicas Mecas en ultra mar. No tenemos en nuestro corto pasado genios artísticos que nos guíen (ni tiranicen). Los antiguos Cuzcos y Palenques y Tenochtitlanes se derruyeron (y tampoco somos más de sola raza roja). Veamos claro lo urgente que es romper las cadenas invisibles (las más fuertes son) que en tantos campos nos tienen aún como COLONIA, a la gran AMÉRICA IBÉRICA con 90 Millones de habitantes. (Artundo, 2001: 3) 
También hay que hacer mención al hecho de que el artista construye su contacto con la iconografía precolombina a partir de la mirada europea, así lo confirman los ejemplares de su biblioteca personal (7), además de los estudios que realizó en 1912 y más tarde en 1919 de las piezas referidas a dicho período histórico conservadas en el Museo Británico de Londres. Por lo tanto, su obra establece vínculos con el pasado latinoamericano, pero, a diferencia de la mirada europea cargadas de exotismos y otredades, aquí se manifiesta una operatoria de apropiación y reactualización de los motivos precolombinos (Armando y Fantoni, 1997).

Como se observa en la obra País, Xul Solar organiza la composición con una figura central serpentina que recorre el espacio plástico. El pasado (ubicado a la izquierda en las líneas de tiempo) es observado por todas las cabezas a excepción de la última que observa hacia abajo. Es hacia ese pasado originario donde dirige la mirada el autor, las subunidades que conforman la serpiente, sostienen todas ellas distintos estandartes correspondientes a las naciones latinoamericanas. Entre las banderas que se pueden identificar figuran los países de Uruguay, Chile, Argentina, Colombia, Paraguay, Perú, Ecuador, República Dominicana, Cuba, Haití, Brasil, Venezuela, Honduras, Guatemala, Panamá, Costa Rica, El Salvador (8), México y Nicaragua. Xul Solar responde a la balcanización americana, o división de estados independientes, al proponer la utopía de una Latinoamérica unida por el cuerpo de la serpiente. Tal fue la preocupación del artista por la integración de los pueblos latinoamericanos que ideó y confeccionó especialmente una bandera que representara a toda la región:

\begin{abstract}
Xul vivía obsesionado con la unidad latinoamericana. Había hecho una Bandera para Latinoamérica. Está integrada por los colores del arcoíris, pero no están agrupados, son tiras sueltas, como si fueran un estandarte, y eso tendía a explicar la necesidad de dichas naciones, al mismo tiempo que concertadas, fueran también un todo orgánico. En ese sentido, Xul es un precursor de la unidad de nuestra américa como lo fue Yrigoyen, como lo fue Dellepiane (Abós, 2017: 240).
\end{abstract}

En la obra conviven la heráldica medieval, las representaciones astrales egipcias, las constelaciones occidentales y la serpiente emplumada de América Central (Polo Dowat, 2012), todos estos motivos reúnen lo celestial y lo divino; pues el artista tenía como "objetivo último: integrar los países de América como nación espiritual de los neocriollos" y esto se evidencia en su producción plástica en la que "proyecta maneras de unir lo dividido, de disolver las fronteras que separan y crear formas que respondan a esta nueva configuración integrada" (Gil, 2014: 95). Para finalizar, cabe señalar que no existen en Xul Solar proclamaciones políticas públicas o lineamientos partidarios (Abós, 2017) (9) como sí se ven en el caso de sus compañeros como 
Marechal, Scalabrini Ortiz o Borges. La problemática acerca de la identidad no la discute desde el ámbito político partidario sino en el ámbito cultural y artístico, desde allí configura simbologías que construyen y sostienen una posible unidad latinoamericana, antiimperialista y autónoma. $Y$ esto le confiere, en última instancia, un claro componente político a su obra.

\section{Conclusión}

En este artículo hemos descrito algunos de los vínculos que Xul Solar mantiene con la escena artística y cultural del país, y del extranjero, los cuales nos permiten hablar de su visión acerca de la idea de identidad latinoamericana así como el lugar privilegiado de los medios de prensa de la época.

La importancia de la participación de Xul Solar en el ámbito intelectual, y en la producción y consumo de los productos gráficos de principios de siglo XX, es central en este debate. Explica en gran medida el afán de integrar elementos de la contemporaneidad a sus obras, propone reflexionar acerca de la potencialidad de las imágenes en clave política, ya sea desde el contacto con las masas populares o como solución a requisitorias simbólicas específicas de proyectos utópicos.

Por ejemplo, el análisis de la pintura País manifiesta las tensiones y cuestionamientos que emergen en torno a los debates por la identidad de los pueblos de América Latina. En este sentido, se puede pensar si es posible una Latinoamérica unida o si es correcto hablar de una identidad Latinoamericana. Esta obra en particular funciona en tanto documento histórico, a la vez, que interpela nuestra visión actual sobre el pasado y sobre los futuros posibles como pueblo Latinoamericano.

Si tenemos en cuenta las tres imágenes analizadas como parte de un mismo proceso, se observan los distintos matices de la problemática acerca de la identidad latinoamericana en términos de un debate historiográfico: el papel de los intelectuales, el rol de los artistas y la modernidad, la idea de progreso, el proyecto utópico, el pasado común, el ser nacional, la balcanización de América Latina, el encuentro de lo local y lo global y la emancipación Latinoamericana. A la vista de dichos debates, y de la participación activa de Xul Solar dentro del campo de la prensa gráfica, carga a su propuesta estética de otras interpretaciones más allá de lo fantástico, del surrealismo o lo religioso; existe sin lugar a duda una gran carga simbólica de representación que lo acerca a la política y, deja entrever cómo la modernidad se asimiló en aquel momento particular en Argentina. 


\section{Imágenes}

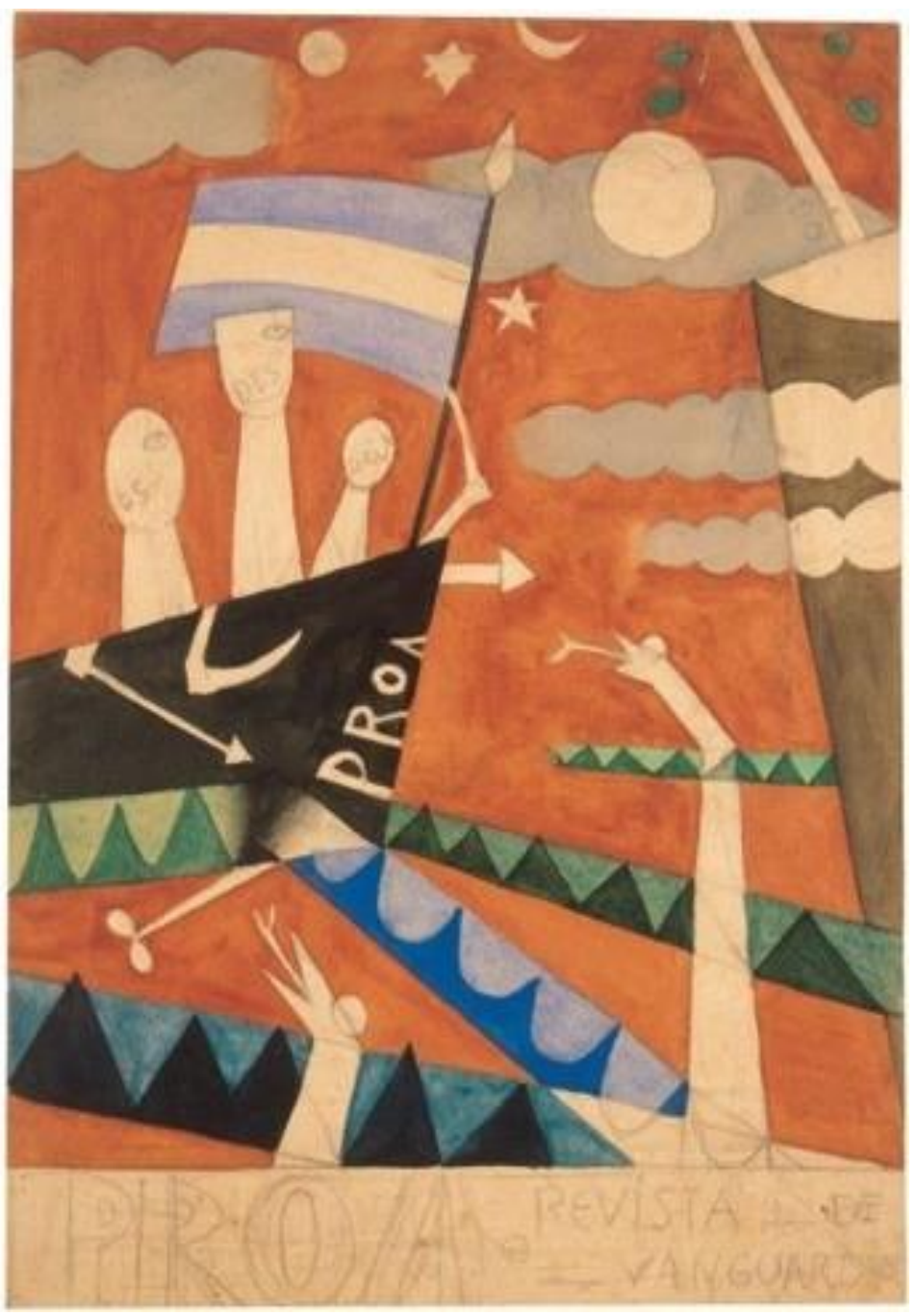

Figura 1: PROA ca. Boceto, 1925, Xul Solar. Gouache sobre papel $50 \times 30 \mathrm{~cm}$ (Fundación Pan Klub, Buenos Aires). 
(2) $\odot \Theta \Theta$

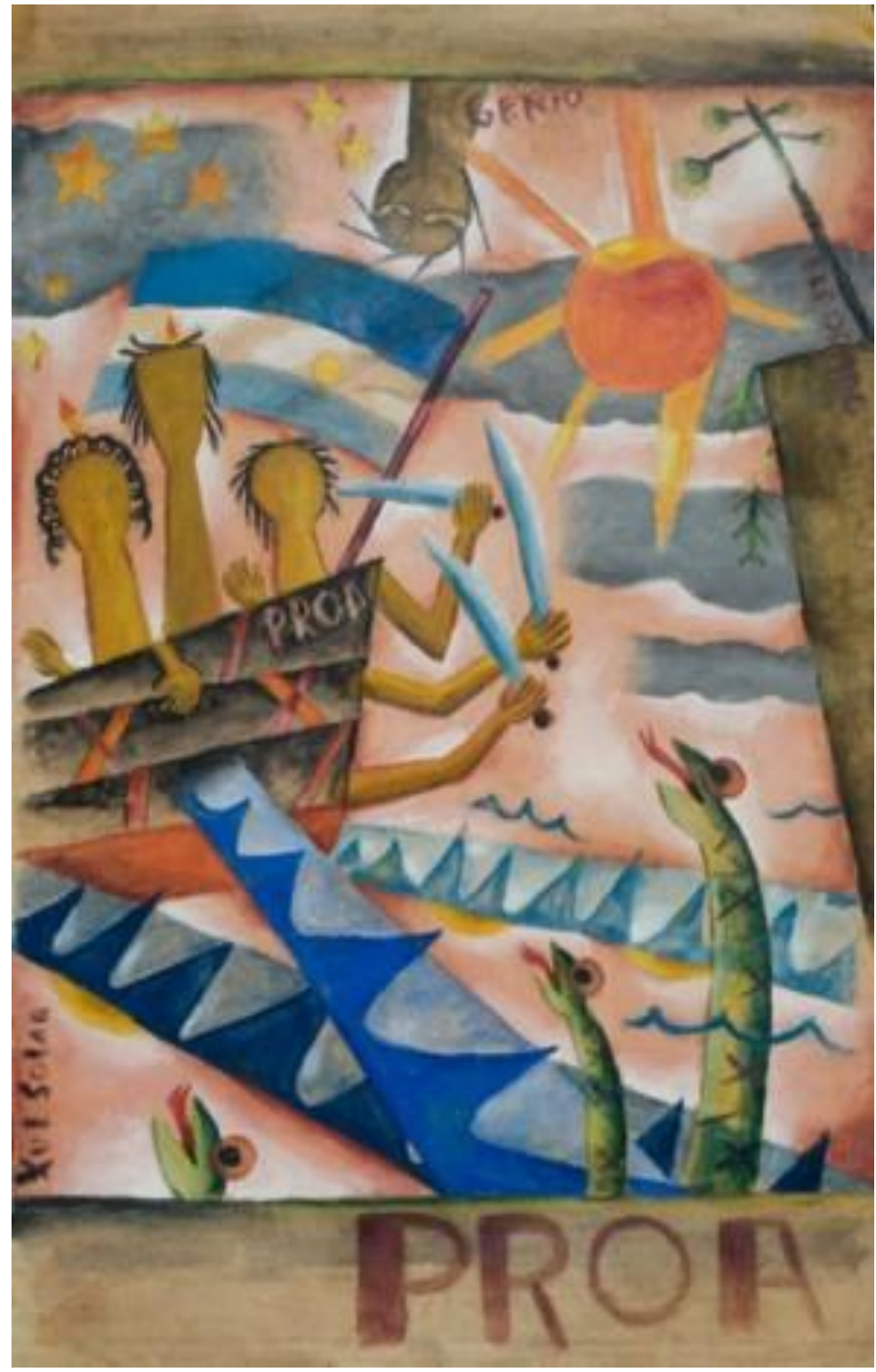

Figura 2: PROA, 1925, Xul Solar. Acuarela sobre papel 50 × $33 \mathrm{~cm}$ (Colección Museo Nacional de Bellas Artes, Buenos Aires). 


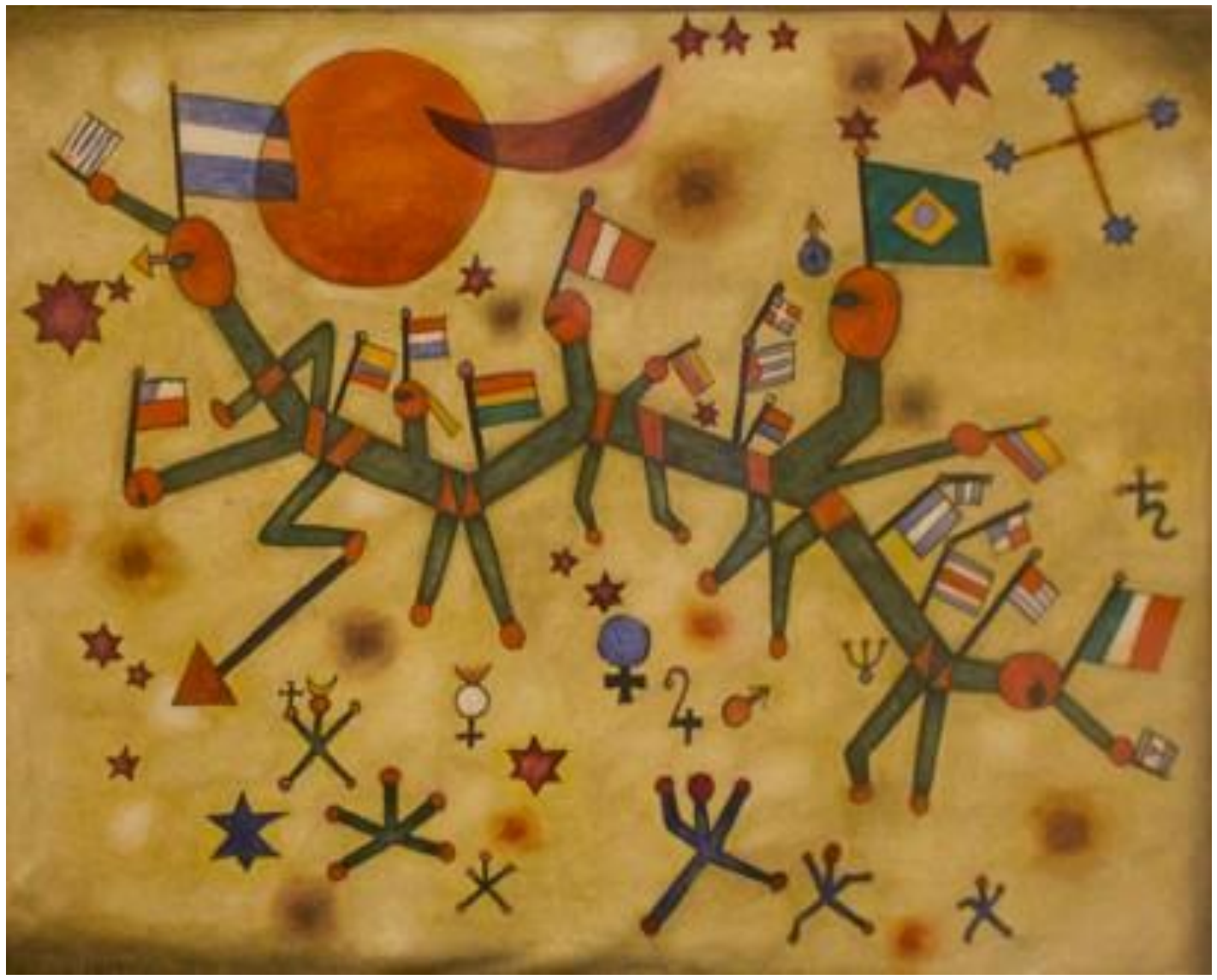

Figura 3: País, 1925, Xul Solar. Acuarela y gouache sobre papel sobre cartón 25,2 x 32,7cm. (Colección particular).

\section{Notas}

(1) Xul Solar escribe por primera vez en la revista Martín Fierro una reseña sobre la muestra de Pettoruti en la galería Witcomb. En el artículo se presenta a sí mismo como pintor-escritor. Xul Solar (1924). Pettoruti. Martin Fierro: Periódico quincenal de arte y crítica libre, 1(10-11), pp. 67, 73-74.

(2) Revista El Mosquito (1863-1893), Caras y Caretas (1898-1941), Don Quijote (1884-1904), Fray Mocho (1912-1929). El caso más relevante en cuanto a la participación política es Don Quijote, en cuyas tapas se mostraba a favor la revolución del Parque de 1890, y en Agosto del mismo año hace un número especial dedicado a las víctimas del suceso que encabezó Alem, entre otros.

(3) En la muestra Xul Solar Panactivista un núcleo curatorial se dedicó especialmente a los intercambios entre el lenguaje musical y el visual. Entre las obras seleccionadas se encontraban: Musical (1924), San Danza (1925) y obras más tardías como Cinco Melodías (1949), Barreras Melódicas (1948), Contrapuntos de puntas (1948). Dice Xul Solar (Artundo, 2017: 103): "Como música escrita, relaciones entre masas, líneas representan al tiempo. Algunos diagramas eisocurvas son puras melodías, como un bello dibujo es polifónico". 
(4) En el mismo sentido de Rueda relaciona el concepto de utopía en su carácter positivo, antropocéntrico y humanista que afecta a los artistas plásticos del veinte, entre ellos Xul Solar. Así también la idea de lugar es pensada a partir del espacio urbano, lo cual también es aplicable a la obra de este autor, especialmente, en aquellas que presentan espacios edificados y fachadas.

(5) Xul Solar fue invitado por Antônio de Alcântara Machado a participar de la primera edición de la revista Antropofagia de 1928. La relación se evidencia en la utilización de los orígenes primitivos, por un lado a través del uso de la lengua, y por otro, en la idea de devorar lo europeo, no de rechazarlo, sino de hacerlo cuerpo y transformarlo.

(6) Pettoruti sentía la necesidad de intentar en su país "la formación de un arte decorativo americano", basado "en la utilización de elementos de nuestro arte primitivo. En el arte incaico, en el azteca, existe un venero inagotable de motivos pictóricos. El gaucho es esencialmente decorativo. Sus prendas engalanan pintorescamente su figura" (Artundo, 2001:6).

(7) De los ejemplares que constan de ese momento, se pueden nombrar A Short Guide to the American Antiquies in the British Museum (1912). Londres y el Handbook to the Ethnographical Collections (1910), Londres. Sobre los libros que trasladó consigo desde Europa consta una lista de ellos, en el registro aduanero solicitado para ingresar a la República Argentina, menciona los siguientes libros y revistas referidos a la temática precolombina, esencialmente a la cultura mexicana. Reich der Inka. Textteil: Sprache und Kultur im ältesten Peru. Bildteil: Keramik, Weberei und Monumentalbau (Imperio del Inca. Lenguaje y cultura en el antiguo Perú. Láminas: Cerámica, textiles y construcciones monumentales); Mexico. Textteil: Grundzüge der altmexikanischen Geisteskultur. Bildteil: Altmexikanische Bilderschriften (México. Rasgos básicos del espíritu de la cultura del antiguo México. Láminas: Descripción de imágenes del antiguo México); Mexico. Textteil: Kultur und Leben im alten México. Bildteil: Mexikanische Plastik (México. Cultura y vida en el antiguo México. Láminas: Plástica mexicana); Mexico. Textteil: Über die religiösen Kulte, Tonatiu, Mexikanische Gebete. Bildteil: Mexikanische Plastik II (México. Sobre los cultos religiosos, oraciones mexicanas. Láminas: Plástica mexicana II), y Mexico. Katalog (México. Catálogo). En la colección Orbis Pictus (Biblioteca del Arte mundial): Mexikanische Kunst. Altmexikanische Kunstgeschichte. Ein Entwurf en Umrissen (Arte mexicano. Historia del arte del antiguo México. Introducción general]).

(8) El artista utiliza una bandera antigua, en realidad la bandera del El Salvador que rige a partir de 1912. El cuadrado rojo con variantes es incorporado en 1865 hasta 1912. Suponemos que el reemplazo encuentra su fundamento por el parecido con las banderas de Nicaragua y Honduras.

(9) La única participación pública en política fue en 1946 cuando firma un manifiesto junto a Marechal, Scalabrini, Carlos Astrada y otros, contra el Libro Azul difundido por el gobierno de los Estados Unidos en oposición al General Perón.

\section{Bibliografía}

Abós, A. (2017). Xul solar: pintor del misterio. Buenos Aires: Sudamericana.

Altamirano, A. y Sarlo, B. (1983/1997). Ensayos argentinos de sarmiento a la vanguardia (Segunda edición). Buenos Aires: Espasa Calpe. Recuperado de https://bit.ly/2A3sRfA

Armando, A. y Fantoni, G. (1997). Dioses y códices prehispánicos en la obra de Xul Solar. Ciencia Hoy, VII(37). 
Artundo, P. (2001). Los años veinte en la argentina. El ejercicio de la mirada. Ciberletras, III(3).

Artundo, P. (2017). Entrevistas, artículos y textos inéditos: Alejandro Xul Solar. Buenos Aires: Corregidor.

Cristía, C. (2007). Xul solar, un músico visual. La música en su vida y su obra. Buenos Aires: Gourmet musical.

De Rueda, M. A. (2003). Arte y utopía. La ciudad desde las artes visuales. Buenos Aires: Asunto impreso.

Fischler, V. (2005). Xul solar, 2 años 229 libros. (Tesis de Licenciatura). Facultad de letras y ciencias sociales, Universidad de Palermo.

Gallo, E. (2006). Prensa política: La historia del radicalismo a través de sus publicaciones periódicas (1890-1990). Buenos Aires: Dunken.

Gil, S. (2012). Las utopías de integración de Xul Solar: Unión americana y disolución de fronteras entre pintura y escritura. VII Congreso Internacional de Teoría y Crítica Literaria Orbis Tertius, Facultad de Humanidades y Ciencias de la Educación, Universidad Nacional de La Plata. Recuperado de https://bit.ly/2GiVJ9t

Gil, S. (2014). Xul solar: Un pintor martinfierrista hacia la identidad americana y la integración entre palabra e imagen. Celehis, 28. Recuperado de https://bit.ly/2URaXpt

Gil, S. (2017). Xul solar: Montajes palabras/imagen en una utopía latinoamericana. (Tesis Doctoral inédita). Doctorado en Letras, Universidad Nacional de Mar del Plata.

Grüner, E. (2004). El conflicto de la(s) identidad(es) y el debate de la representación la relación entre la historia del arte y la crisis de lo político en una teoría crítica de la cultura. La Puerta, 1(1), pp. 58-68. Recuperado de https://bit.ly/2QXyWnl

Larraín, J. (1997). Modernidad e Identidad en América Latina. Universum. Revista de humanidades $y$ ciencias sociales, 12 . Recuperado de http://universum.utalca.cl/contenido/index-97/larrain.html

Polo Dowat, G. (2012). XUL SOLAR, un referente del orden simbólico americanista. (Tesis de doctorado). Facultad de Artes, Universidad Nacional de Misiones, Formosa, Argentina y Facultad de Bellas Artes de la Universidad de Granada, España. Recuperado de https://bit.ly/2SaMDNa

Rabossi, C. (2017). Xul solar panactivista. Ciudad Autónoma de Buenos Aires: Asociación de Amigos del Museo Nacional de Bellas Artes.

Sarlo, B. (1988). Una modernidad periférica: Buenos Aires 1920 y 1930. Buenos Aires: Nueva Visión.

Sarlo, B. (2002). El caso Xul Solar. Invención fantástica y nacionalidad cultural. En Barnatán, M. 
y Díaz de Rábago Cabeza, B. (coord.). Xul Solar (pp-45-55). Madrid: Museo Nacional Centro De Arte Reina Sofía.

Smart, A. (2010). La estética de lo posible en la pintura de Xul Solar. Páginas De Filosofía, $\begin{array}{llll}X I(14), & \text { pp. } & \text { 82-109. } & \text { Recuperado de }\end{array}$ http://revele.uncoma.edu.ar/htdoc/revele/index.php/filosofia/article/view/ 47/46

Solar Xul, A. Pettoruti. Martin Fierro: Periódico quincenal de arte y crítica libre, 1(10-11), pp. 6774.

Tedín de Tognetti, T. (2006). Biografía de Xul Solar. En Artundo, P. (coord.). Xul Solar. Visiones y revelaciones. Buenos Aires: Malba-Colección Constantini. Recuperado de http:// www.xulsolar.org.ar/biografia.html 